\title{
EL RÉGIMEN DE LOS CONVENIOS PARA EL FOMENTO DE ACTIVIDADES DE CIENCIA, TECNOLOGÍAE INNOVACIÓN *
}

\section{The public procurement system for the development of science, technology and innovation}

Alejandro Gómez Velásquez**

Cristian Andrés Díaz Díez ***

Recepción: 3 de julio de 2020. Aceptación: 3 de febrero de 2021

DOI: http://dx.doi.org/10.21017/Rev.Repub.2021.v30.a98

\section{RESUMEN}

El presente artículo tiene como objeto analizar el régimen de los contratos o convenios que se dirigen a fomentar la Ciencia, la Tecnología y la Innovación por parte de entidades estatales. Para ello, se recurre a la dogmática jurídica, con el fin de ofrecer un análisis sistemático del régimen en cuestión, acudiendo para ello a fuentes normativas, jurisprudenciales y doctrinales. A partir del análisis, se sostendrá que el régimen contractual de la Ciencia, la Tecnología y la Innovación tiene dos características principales. Por un lado, es un régimen especial, en razón a que constituye una de las causales de contratación directa previstas en el Estatuto General de Contratación de la Administración Pública. Por otro, es un régimen reglado, es decir que el ordenamiento vigente ha regulado con precisión el objeto, los elementos esenciales, los de la naturaleza, los accidentales y las tipologías de los convenios a celebrarse, relacionados con dicha materia.

Palabras clave: contratación estatal, ciencia, tecnología, innovación, contratos, convenios.

* El presente artículo se inscribe en el proyecto de investigación titulado "Naturaleza y forma de garantía de la transparencia en el ejercicio de la función administrativa en Colombia", aprobado dentro de la convocatoria de proyectos de financiación interna, 2018, de la Universidad EAFIT, Grupo de Investigación Derecho y Poder.

** Doctor en Derecho en la Universidad Pompeu Fabra, España. Profesor e investigador de tiempo completo de la Escuela de Derecho de la Universidad EAFIT, Colombia. Correo electrónico: agomezv1@eafit.edu.co, Google Scholar, ORCID: 0000-0002-6354-5708.

*** Magíster en Derecho de la Universidad de Antioquia, Colombia. Profesor e investigador de tiempo completo de la Escuela de Derecho de la Universidad EAFIT, Colombia. Correo electónico: cdiazdi@eafit.edu.co, Google Scholar, ORCID: 0000-0001-9139-6941. 


\begin{abstract}
The following paper aims to analyze the legal framework of public procurement for the development of activities related to science, technology and innovation. Through legal research methods, the paper proposes a systematic analysis of the legal framework recurring to normative, jurisprudence and doctrinal sources. It will be held that the contractual legal framework has two main features. On one hand, is special because it is an exception for direct awarding in the Colombian public procurement system. On the other, it is a regulated framework, meaning that the legal system defines in detail the object, essential aspects and typology of the contracts and award in this regard.
\end{abstract}

Key words: public procurement, science, technology, innovation, contracts, awards.

\title{
INTRODUCCIÓN
}

A raíz de la pandemia global generada por el Covid-19 se ha reivindicado con especial fuerza la importancia de los desarrollos científicos, tecnológicos y de innovación para asuntos tan cruciales como para nuestra supervivencia como especie. En Colombia existe consenso en torno a la necesidad de fortalecer el sector de la Ciencia, la Tecnología y la Innovación (de aquí en adelante CTeI), el cual se ha fortalecido a raíz de la necesidad de implementar medidas para el tratamiento, la contención y la mitigación de los efectos de la pandemia que estén respaldadas por evidencia científica y tecnológica. En esta dirección, se orientó la aprobación y sanción de la Ley 1951 de 2019, por la cual se crea el Ministerio de Ciencia, Tecnología e Innovación como una nueva estrategia para fortalecer el Sistema Nacional del mismo nombre. Junto con las reformas institucionales, uno de los instrumentos de administración pública más decisivos para el buen desempeño de un sector lo constituye la gestión contractual (Shick, 2016), la cual ha debido adecuarse a las circunstancias causadas por la pandemia (Mondragón, Flórez \& Plazas, 2020). Por lo tanto, si lo que se pretende es contribuir al fomento de la CTeI, resulta relevante y pertinente indagarnos por el régimen contractual existente para el sector.

Pretender que este tipo de contrataciones sea ágil en su celebración, que pueda someterse a condiciones especiales, atendiendo a su especificidad, y que exista una mayor flexibilidad en los modelos de asociación con la comunidad científica y tecnológica del país, parece ser la finalidad que debe orientar el régimen jurídico especial que rige a este tipo de contrataciones. 
Sin embargo, en los últimos años hemos visto cómo, en ciertos casos incluso de connotación nacional, se ha utilizado dicho régimen como mecanismo para eludir los procedimientos públicos de selección y proceder a contratar «a dedo» cuantiosos contratos que, en realidad, no tenían como objeto directo el desarrollo de actividades de CTeI. Ello ha generado la atribución de responsabilidades en el ámbito disciplinario, fiscal, político e incluso penal para quienes intervinieron en su celebración. Por lo tanto, recientemente, se percibe cierta inseguridad jurídica en la utilización de dichas modalidades especiales de contratación estatal por parte de los operadores jurídicos, lo cual puede llegar a afectar, precisamente, el fomento de la CTeI, que, como se ha dicho, resulta tan necesaria en nuestro país.

Las razones indicadas anteriormente justifican, por tanto, un estudio riguroso del régimen especial de los convenios y contratos de CTeI, con el objetivo de elaborar un rastreo de tipo normativo, jurisprudencial y doctrinario, que permita plantear un estado del arte sobre su regulación actual. Asimismo, se busca ofrecer algunas alternativas de interpretación sobre algunos temas problemáticos en la configuración normativa de los mencionados contratos y convenios. La intención con ello es que estos puntos de vista sean útiles para el operador jurídico o al menos sigan propiciando reflexiones al respecto.

Con estas ideas en mente, el presente artículo se estructura en tres apartados. En el primero de ellos, se abordará la definición legal de las actividades de CTeI. Para ello, se identificará el marco normativo aplicable y las actividades que son objeto del régimen especial de contratación. En una segunda parte, se analizarán las características de los contratos y convenios de CTeI. Al hacerlo, se definirá si se trata de contratos estatales, su relación con el Estatuto General de Contratación de la Administración Pública (de aquí en adelante EGCAP) y el procedimiento de selección del contratista, entre otras características. Posteriormente, en un tercer apartado, se expondrán las distintas tipologías de contratos o convenios de CTeI que se establecen en el régimen contractual vigente.

\section{PROBLEMA DE INVESTIGACIÓN}

El problema jurídico se refiere a identificar el régimen jurídico vigente de los convenios y contratos de CTeI en Colombia, haciendo especial énfasis en fuentes de carácter normativo, jurisprudencial y doctrinario, que permita plantear un estado del arte sobre su regulación actual. De esta manera, se busca ofrecer algunas alternativas de interpretación sobre temas problemáticos en la configuración normativa de los mencionados contratos y 
convenios. La intención con ello es que estos puntos de vista sean útiles para el operador jurídico o al menos sigan propiciando reflexiones al respecto.

\section{ESTRATEGIA METODOLÓGICA}

El presente escrito responde a una investigación de dogmática jurídica de lege lata (Courtis, 2006, p. 114), que pretende identificar los problemas interpretativos en el régimen de los convenios para el fomento de actividades de ciencia, tecnología e innovación en Colombia y se propone señalar soluciones adecuadas a los mismos a partir del derecho positivo vigente. En este sentido, su orientación pretende ser tanto descriptiva como prescriptiva o normativa, ya que pretende exponer razones para inducir a los operadores jurídicos a preferir la interpretación que se propone sobre otras posibles.

Para ello se utilizarán tres fuentes principales de la investigación dogmática. En primer lugar, el derecho positivo vigente, tanto a nivel constitucional, legal y reglamentario que compone el régimen de los contratos de ciencia, tecnología e innovación en Colombia. En segundo lugar, se hará referencia a la jurisprudencia, tanto, como criterio vinculante al provenir de las Altas Cortes y constituirse en precedente judicial, como criterio auxiliar al provenir de otras autoridades judiciales o de control. En tercer lugar y como fuente auxiliar se analizará la doctrina especializada en la materia, a saber, la relativa a la contratación estatal y/o administrativa colombiana.

\section{RESULTADOS}

Tras la investigación dogmática realizada los principales resultados y hallazgos pueden sintetizarse afirmando que i) existe una definición legal de las Actividades de Ciencia, Tecnología e Innovación en el sistema jurídico colombiano; ii) Los contratos y convenios de CTeI son contratos estatales; iii) están sujetos al Estatuto General de Contratación de la Administración Pública (EGCAP); iv) constituyen una causal de contratación directa; v) no admiten el pacto y utilización de cláusulas excepcionales; vi) requieren de estudios previos y de liquidación, entre otras figuras propias de los contratos regidos por el EGCAP; vii) no se requiere que el contratista esté inscrito en el Registro Único de Proponentes (RUP); y viii) la legislación vigente establece cuatro tipos diferentes de contratos de CTeI a saber: los convenios especiales de cooperación, los convenios de financiamiento del desarrollo de actividades de CTeI, los contratos para la administración de proyectos y los contratos y convenios celebrados con recursos del Fondo Francisco José de Caldas. 


\section{DISCUSIÓN}

\section{Definición legal de las Actividades de Ciencia, Tecnología e Innovación}

A la luz de los artículos 69, 70 y 71 de la Constitución Política, el Estado colombiano tiene el deber de fortalecer, fomentar y promover el desarrollo de la ciencia y la tecnología. Para ello, debe crear y ofrecer incentivos para que personas naturales e instituciones ejerzan y desarrollen actividades científicas y tecnológicas. En el lenguaje ordinario, el concepto de ciencia guarda relación con el estudio metódico y sistemático que con el curso de la actividad de investigación desarrolla una serie de principios generales. Cuando las técnicas no proceden de actividades científicas, se está en presencia del desarrollo de actividades simplemente tecnológicas (Matallana, 2009, p. 738).

En ejecución de estas disposiciones constitucionales, el Congreso de la República expidió inicialmente la Ley 29 de 1990. En materia contractual, dicha norma otorgó facultades extraordinarias para que fuera el Gobierno Nacional quien regulara las modalidades contractuales específicas para el fomento de actividades científicas y tecnológicas, tal y como lo dispone el artículo 11.4 de la mencionada norma. En virtud de dichas facultades, el Gobierno Nacional expidió los Decretos-Ley 393 y 591 de 1991. El último de ellos, en su artículo 2. ${ }^{\circ}$, determinó de forma precisa y taxativa lo que debe entenderse por actividades de ciencia y tecnología, a saber:

1. Investigación científica y desarrollo tecnológico, desarrollo de nuevos productos y procesos, creación y apoyo a centros científicos y tecnológicos y conformación de redes de investigación e información.

2. Difusión científica y tecnológica, esto es, información, publicación, divulgación y asesoría en ciencia y tecnología.

3. Servicios científicos y tecnológicos que se refieren a la realización de planes, estudios, estadísticas y censos de ciencia y tecnología; a la homologación, normalización, metrología, certificación y control de calidad; a la prospección de recursos, inventario de recursos terrestres y ordenamiento territorial; a la promoción científica y tecnológica; a la realización de seminarios, congresos y talleres de ciencia y tecnología, así como a la promoción y gestión de sistemas de calidad total y de evaluación tecnológica.

4. Proyectos de innovación que incorporen tecnología, creación, generación, apropiación y adaptación de la misma, así como la creación y el apoyo a incubadoras de empresas, a parques tecnológicos y a empresas de base tecnológica. 
5. Transferencia tecnológica que comprende la negociación, apropiación, desagregación, asimilación, adaptación y aplicación de nuevas tecnologías nacionales o extranjeras.

6. Cooperación científica y tecnológica nacional e internacional.

Atendiendo a los desarrollos normativos posteriores, este listado deberá integrarse de forma sistemática (Colombia Compra Eficiente, 2013) con las actividades previstas en el artículo 2..$^{\circ}$ del Decreto 393 de 1991 y en el artículo 18 de la Ley 1286 de 2009. Hecha esta integración normativa deberá concluirse que, al existir definición legal al respecto y ser este un régimen contractual especial, ello conlleva que deba a hacerse una interpretación restrictiva de las actividades reguladas por este régimen especial ${ }^{1}$. Al respecto, ha señalado el Consejo de Estado (2009):

\section{A fin de determinar la aplicación de estas normas especiales, que individualizan y caracterizan los contratos aludidos, debe acudirse a la definición que el artículo $2 .^{\circ}$ del Decreto Ley 591 de 1991 (en concordancia con los artículos 1. y 2. del Decreto 393 de 1991) realiza de las actividades científicas y tecnológicas susceptibles de contratar.}
(...) De acuerdo con la norma transcrita, el régimen especial se aplica cuan- do los contratos enunciados tienen por objeto el desarrollo de cualquiera de las anteriores actividades, lo que, por consiguiente, excluye aquellas que no encuadren en alguna de ellas o les sean meramente de auxilio o apoyo.

Por lo tanto, en virtud de la especialidad del régimen en cuestión, en caso de duda sobre si el objeto de un contrato en particular hace parte del catálogo de actividades definidas como de ciencia y tecnología, se sugiere consultar al Departamento Administrativo de Ciencia, Tecnología e Innovación, COLCIENCIAS (Colombia Compra Eficiente, 2013) o próximamente al Ministerio de Ciencia, Tecnología e Innovación. Ello, en tanto, ambas entidades, en su calidad de órganos coordinadores del Sistema Nacional de CTeI, tienen dentro de sus funciones orientar a los diferentes actores del sistema sobre el alcance y las modalidades contractuales que se utilicen en el sector ${ }^{2}$.

1 En el mismo sentido, el artículo 2.2.1.2.1.4.5 del Decreto 1082 dispone: «La contratación directa para el desarrollo de actividades científicas y tecnológicas debe tener en cuenta la definición contenida en el Decreto-Ley 591 de 1991 y las demás normas que lo modifiquen, aclaren, adicionen o sustituyan». Decreto 1082 de 2015. Por medio del cual se expide el Decreto Único Reglamentario del Sector Administrativo de Planeación Nacional. Mayo 26 de 2015.

2 En los procesos y procedimientos adelantados para determinar la responsabilidad derivada de la celebración de convenios o contratos de CTeI, se le ha venido dando gran 
Tras las modificaciones introducidas por la Ley 1289 de $2009^{3}$ al Sistema de Ciencia y Tecnología, transformándolo en el Sistema Nacional de Ciencia, Tecnología e Innovación (SNCTI), se suscita la pregunta acerca de lo que debe entenderse por actividades de innovación y si sobre estas también opera el régimen contractual especial. Si bien no existe una definición legal al respecto, como sí la hay para las de ciencia y tecnología, de una lectura sistemática y teleológica de la ley puede afirmarse que dichas actividades se refieren a la creación y el desarrollo de nuevos productos y servicios, tendientes a la transformación, la modernización y la reconversión del aparato productivo nacional, buscando incrementar su productividad y competitividad, tanto a nivel nacional como internacional ${ }^{4}$. Sobre el régimen contractual de las actividades de innovación, del texto del artículo 33 de la Ley 1289 de 2009 puede afirmarse que los convenios y los contratos que tengan a estas como objeto, también se regirán por las normas especiales, es decir, las del Decreto 393 y 591 de 1991, y demás normas concordantes 5 .

Sobre el desarrollo de actividades de CTeI, el profesor Dávila Vinueza (2016, p. 505) considera que la justificación del régimen jurídico especial que las cobija no debe entenderse dirigida únicamente a la ejecución de estas, sino que además se exige que su finalidad sea el desarrollo y fomento de las mismas. En la misma línea, sostiene Pino Ricci (2005, p. 243) que los contratos para la simple difusión de informes científicos, la adquisición de elementos que se destinarán a la realización de actividades científicas, etc. no podrán celebrarse directamente mediante la excepción prevista para la realización de esta clase de actividades. En una interpretación coincidente, la Corte Suprema de Justicia (2014) ha sostenido que para que se pueda utilizar esta modalidad contractual el objeto directo y concreto deberá ser la generación de CTeI, y no que esta sea una mera actividad de apoyo a ese propósito directo o la forma como se desarrolla el negocio jurídico.

relevancia a los conceptos que al respecto emita COLCIENCIAS sobre el alcance de los objetos contratados. Al respecto véase: Procuraduría General de la Nación. Proceso D2014-120-684737. (P. Irma Trujillo Ardila; abril 16 de 2016).

3 Ley de 1286 de 2009. Por la cual se modifica la Ley 29 de 1990, se transforma a Colciencias en Departamento Administrativo, se fortalece el Sistema Nacional de Ciencia, Tecnología e Innovación en Colombia y se dictan otras disposiciones. Enero 23 de 2009.

$4 \mathrm{Al}$ respecto, deben revisarse los propósitos descritos por el artículo $3 .^{\circ}$ y las actividades establecidas en el artículo 18 de la Ley 1289 de 2009. Op. Cit. De igual forma puede tenerse como referente para la determinación de estas actividades las establecidas en la Guía para la recogida e interpretación de datos sobre innovación, más conocida como el Manual de Oslo, editado conjuntamente por la OCDE y EUROSTAT.

5 Colombia Compra Eficiente ha venido haciendo recomendaciones para la estructuración de procesos de «Compra Pública para la Innovación», los cuales se han enmarcado como convenios o contratos de CTeI. Al respecto véase: http:/ / www.colombiacompra.gov.co/ sites/cce_public/files/cce_documentos/20161130_manual_de_compra_publica_ para_la_innovacion.pdf 


\section{Características de los Contratos y Convenios de Ciencia y Tecnología}

\subsection{Los contratos y convenios de CTeI son contratos estatales}

El EGCAP, en su artículo 32, define los contratos estatales como «todos los actos jurídicos generadores de obligaciones que celebren las entidades a que se refiere el presente estatuto, previstos en el derecho privado o en disposiciones especiales, o derivados del ejercicio de la au tonomía de la voluntad, así como los que a título enunciativo se definen a continuación...». De esta definición se desprende claramente que los contratos y convenios de CTeI constituyen una especie de contratos estatales, pues son actos jurídicos generadores de obligaciones, en los que al menos una de las partes es una entidad estatal, y además están definidos como contratos por leyes especiales.

\subsection{Los contratos y convenios de CTeI están sujetos al Estatuto General de Contratación de la Administración Pública}

A pesar de reconocerse como contratos estatales, se ha discutido si el régimen de estos contratos es autónomo al del EGCAP. Sobre este punto, tanto la doctrina como la jurisprudencia constitucional, administrativa y penal, han coincidido en señalar que ello no es así. Por lo tanto, salvo las disposiciones especiales previstas en los Decretos-Ley 393 y 591 de 1991, para los demás asuntos contractuales deberá atenderse a lo dispuesto por EGCAP y las demás leyes que la modifican y la adicionan.

Para justificar esta posición, sea lo primero señalar que la Ley 80 no derogó en su integridad el Decreto-Ley 393 de 1991, pues, como lo anotó la Corte Constitucional (1995) al estudiar la exequibilidad de varias de sus disposiciones, mediante Sentencia C-316 del 19 de julio de 1995, y respaldar con ello también la vigencia de esta normativa, «...el Decreto 393 no constituye propiamente un estatuto de contratación. Simplemente prevé entre los mecanismos de asociación para el fomento de la investigación uno especial consistente en la celebración de convenios de cooperación; de ahí la razón por la cual la Ley 80 de 1993 no se ocupó de derogar tal reglamentación...». En este sentido, coincide Chávez Marín (2015, p. 418), al afirmar que el artículo 81 de la Ley 80 de 1993 deroga expresamente solo algunas disposiciones del Decreto-Ley 591 de 1991; y al ser esta ley posterior, de igual valor y del mismo alcance de dichos decretos-ley, «puede decirse que el legislador de la Ley 80 tuvo la manifiesta intención, expresada en las disposiciones mencionadas de regular los convenios celebrados en materia de ciencia y tecnología».

Por lo tanto, ha considerado la Sala de Consulta del Consejo de Estado (2009) que las disposiciones del Decreto-Ley 591 de 1991 que dejó vigente la Ley 80 
de 1993, respecto de las modalidades de negocios jurídicos en ciencia y tecnología (artículos 2, 8, 9, 17 y 19), no tendrían sentido y aplicación jurídica, si no fueran armonizadas con las materias conexas que disciplina el Decreto-Ley 393 de 1991. Esta es una razón de más para señalar que no fue la intención del citado Estatuto General de Contratación derogarlo expresa o tácitamente.

Siguiendo este mismo razonamiento, ha concluido la Sala Penal de la Corte Suprema de Justicia (2014) que los contratos que se celebren con el objeto de fomentar la CTeI se encuentran sujetos al EGCAP en todos aquellos aspectos sustantivos que no estén expresamente regulados en las normas especiales de los Decretos-Leyes 393 y 591 de 1991. En palabras de la Sala Penal:

[...] una interpretación sistemática y teleológica de estas disposiciones lleva a concluir que la existencia de los Decretos 393 y 591 de 1991 no exime de aplicar, en lo pertinente, la Ley 80 de 1993, más aún si se tiene en cuenta que el primero, en su artículo $9 .^{\circ}$, supedita la celebración de convenios de cooperación entre la administración pública y entidades de este mismo carácter, a que guarden «... conformidad con las normas generales», vale decir con el restante ordenamiento jurídico y de manera especial con el Estatuto General de Contratación de la Administración Pública, en todo aquello que no esté regulado en forma expresa por los Decretos Ley mencionados.

Por último, por si los argumentos anteriores no fueran suficientes, es la misma Ley 1150 de 2007 modificatoria del EGCAP, tal y como se reitera en su reglamento, a saber, el Decreto 1082 de 2015, la que consagra expresamente a las actividades de CTeI como una causal autónoma de contratación directa, como pasa a explicarse.

\subsection{La modalidad de selección para la celebración de los contratos y conve- nios de CTeI es la contratación directa}

Ello se desprende claramente, por un lado, de lo dispuesto por el artículo 2. ${ }^{\circ}$ de la Ley 1150 de 2007, al considerar expresamente como causal de contratación directa a «e) Los contratos para el desarrollo de actividades científicas y tecnológicas». Por otro lado, el mismo artículo 33 de la Ley 1289 de 2009, que modificó parcialmente la Ley 29 de 1990, dispone expresamente que los contratos de CTeI se celebrarán «directamente» ${ }^{6}$. Este razonamiento es igualmen-

6 Art. 33. L.1289/09. «Las actividades, contratos y convenios que tengan por objeto la realización de actividades definidas como de ciencia, tecnología e innovación que celebren las entidades estatales, continuarán rigiéndose por las normas especiales que les sean aplicables. En consecuencia, tales contratos se celebrarán directamente ...]». 
te reiterado por el tenor del artículo 2.2.1.2.1.4.7 del Decreto 1082 de 2015, al reglamentar esta causal particular de contratación directa.

Sobre la justificación de que la contratación sea directa, Pino Ricci (2005, p. 243) sostiene que los contratos de ciencia y tecnología son siempre intuito personae, es decir, se celebran con la persona que mayor idoneidad tiene para el cumplimiento del objeto que hace que el trámite de una licitación o concurso resulte innecesario, pues de antemano los estudios previos han determinado cuál es la persona más adecuada para celebrar el contrato. En este razonamiento coincide Palacio (2004, p. 235) al identificar a dicha causal como una de aquellas que se justifica por la persona del contratista, conduciendo a que se pueda contratar directamente dichos servicios con la persona natural o jurídica que tenga la mayor capacidad de ejecutar el objeto del contrato y que haya demostrado idoneidad y experiencia directamente relacionada con el área de la ciencia y la tecnología.

En este sentido, debe recordarse que, según lo dispuesto por el parágrafo $1 .^{\circ}$ del artículo $2 .^{\circ}$ de la Ley 1150 de 2007, y las correspondientes normas reglamentarias, la entidad estatal contratante deberá realizar una justificación de manera previa a la apertura del proceso, a través de un acto administrativo, que incluya los fundamentos jurídicos y fácticos que soportan la utilización de esta modalidad de selección (Consejo de Estado, 2014). Como causal de contratación directa, debe tenerse en cuenta que, tal y como consta en el régimen legal vigente y en la jurisprudencia, esta, al ser una excepción al procedimiento licitatorio, no solo no debe interpretarse de forma extensiva (Consejo de Estado, 2013), ni ser utilizada para seleccionar el arbitrio de la Administración, sino que, con ella, se impone el respeto de los principios constitucionales (Consejo de Estado, 2017) y legales que inspiran la contratación estatal, incluyendo el de selección objetiva (Consejo de Estado, 2009). Al respecto, valga recordar que el artículo $4 .^{\circ}$ de la Ley 1286 de 2009 establece el principio de transparencia, entre otros principios que rigen la actividad de fomento y estímulo en materia de CTeI, en los siguientes términos:

(...) 5. Transparencia. Las instituciones, programas, proyectos y personas objeto de apoyo, se podrán seleccionar mediante convocatorias públicas, basadas en criterios de mérito y calidad.

Sobre la interpretación particular de dicho principio, surge la inquietud de si dicha mención a la posibilidad de realizar «convocatorias públicas» para celebrar tales contratos hace referencia a un sistema de licitación o concurso plural o a los procedimientos previos que deben celebrarse previamente a la contratación. Al respecto, la Sala de Consulta y Servicio Civil del Consejo de Estado (2009) ha considerado que una interpretación sistemática de los artículos 4.5 y 33 de la Ley 1286 de 2009 lleva a sostener que en los contratos 
cuyo objeto es la realización de actividades de CTeI, la modalidad de selección aplicable será la contratación directa, pero que, en virtud de la regulación precisa que se hace del principio de transparencia, nada obsta para que dicha modalidad de selección pueda instrumentarse mediante convocatorias públicas que permitan pluralidad de ofertas y concurrencia de oferentes, con miras a realizar en la mayor medida posible el principio de selección objetiva ínsito en la contratación pública.

\subsection{En los contratos y convenios de CTeI no se admite el pacto y la utiliza- ción de cláusulas excepcionales}

A la luz de lo dispuesto por el parágrafo único del artículo 14 de la Ley 80 de 1993, en los contratos que tengan por objeto el desarrollo directo de actividades de CTeI se prescindirá de la utilización de las cláusulas o estipulaciones que resulten extrañas al derecho común y que rompan el plano de igualdad entre los contratistas particulares y los contratantes públicos, más conocidas como cláusulas excepcionales. Por lo tanto, en dichos contratos o convenios no podrán establecerse ni ejecutarse cláusulas como las de interpretación, modificación o terminación unilaterales, de caducidad del contrato o de reversión.

En este mismo sentido se ha pronunciado el Consejo de Estado (2012) reconociendo que, por estar proscrito legalmente el pacto de dichas cláusulas excepcionales, en caso que así se haga y se pretendan ejecutar en virtud del poder de autotutela de la administración, dicho acto será declarado ilegal y deberá ser anulado por falta de competencia, $\mathrm{y}$, de haberse solicitado, ordenarse el correspondiente restablecimiento de los derechos conculcados al contratista (Consejo de Estado, 2012) ${ }^{7}$.

\subsection{Los contratos y convenios de CTeI requieren de estudios previos y de liqui- dación, entre otras figuras propias de los contratos regidos por el EGCAP}

Definida la regla, según la cual los contratos y convenios de CTeI se encuentran sometidos al EGCAP en todo lo no regulado por las normas especiales de

7 Al respecto ha dispuesto el Consejo de Estado: «P]ueden pactarse cláusulas excepcionales], aunque no es obligatorio sino discrecional, en los contratos de suministro y prestación de servicios; mientras que está proscrito su acuerdo en aquellos contratos que se celebran con personas públicas internacionales, los de cooperación, los de donación, los de arrendamiento, los que comprendan la realización de actividades científicas o tecnológicas, los de seguros tomados por las entidades estatales y aquellos cuyo objeto sea la ejecución de actividades comerciales o industriales de las entidades que no correspondan a las indicadas en el numeral 2 del artículo 14 de la Ley 80 de 1993». Consejo de Estado. Sala de lo Contencioso Administrativo. Sección Tercera. Expediente 32436. Consejero Ponente: Danilo Rojas Betancourth (octubre 29 de 2015). 
los Decretos-Ley 393 y 591 de 1993, se deriva que a los mismos les serán aplicables las normas relativas a estudios y documentos previos, pagos anticipados, anticipos, adiciones, supervisión y/o interventoría, análisis de riesgos, garantías, entre otras.

Así lo han reiterado los operadores jurídicos, al estudiar este tipo de convenios o contratos. De manera ilustrativa, en sede de un proceso de responsabilidad disciplinaria, la Procuraduría General de la Nación ha considerado como falta disciplinaria gravísima la inexistencia de estudios y documentos previos para un contrato de CTeI, al afirmar que con ello se vulnera el principio de planeación que debe inspirar la contratación estatal (Procuraduría General de la Nación, 2011). De igual forma, en el marco del medio de control de controversias contractuales, el Consejo de Estado (2015) ha considerado que, en ausencia de liquidación bilateral o unilateral de un convenio de CTeI, las partes bien podrán acceder a la jurisdicción administrativa para que sea esta quien liquide definitivamente un convenio de dicha naturaleza. Sobre los plazos para la liquidación y en ausencia de estipulación al respecto, ha señalado esta misma entidad que aplican los plazos supletorios para todo contrato estatal establecidos en el artículo 11 de la Ley 1150 de 2007, los cuales deben interpretarse en concordancia con la caducidad de la acción contractual establecida en el artículo 164 del Código de Procedimiento Administrativo y de lo Contencioso Administrativo, CPACA (Consejo de Estado, 2017).

\subsection{Para los contratos y convenios de CTeI no se requiere que el contratista esté inscrito en el RUP}

De acuerdo con lo dispuesto en la Ley 1150 de 2007, no se requiere que el contratista de un contrato o convenio de CTeI se encuentre inscrito en el Registro Único de Proponentes. Ello es así, ya que, como se dijo, al ser una causal de contratación directa, el artículo $6 .^{\circ}$ de la mencionada ley excluye a los interesados en contratar por estas causales de la obligación de registrarse o calificarse en el Registro Único de Proponentes. Por lo tanto, la verificación de la información relacionada con la experiencia, la capacidad jurídica, financiera y de organización del proponente y su clasificación, deberá hacerse directamente por la entidad contratante con los soportes documentales que considere.

\section{Tipologías de los contratos y convenios de CTeI}

Dentro del régimen especial vigente dispuesto por los Decretos-Ley 393 y 591 de 1991, pueden distinguirse, al menos, cuatro tipos contractuales de carácter 
temporal ${ }^{8}$. Al respecto, encontramos i) el denominado convenio especial de cooperación, ii) el convenio de financiamiento, iii) el contrato de administración de proyectos de CTeI y iv) los demás que se celebren con recursos del Fondo Francisco José de Caldas. Sobre las diferencias entre la denominación de contrato o convenio, la doctrina especializada (Chávez, 2015) y la jurisprudencia (Consejo de Estado, 2014) se han inclinado por considerar a los primeros como aquellos acuerdos de voluntades que encierran una reciprocidad de obligaciones y una equivalencia de las prestaciones asumidas, lo cual suele traducirse en la entrega de un bien o servicio a cambio de una remuneración estipulada. Por su parte, los convenios serán aquellos acuerdos voluntarios dirigidos a aunar esfuerzos a través de la confluencia de aportes para la consecución de los fines entre entidades públicas o estas y un particular que concurre a su celebración persiguiendo los mismos fines, sin que suela existir una contraprestación de por medio. Sin bien, desde una perspectiva estrictamente legal, de dicha distinción no se derivan consecuencias frente a la modalidad de selección de contratista, a continuación, se hará uso de la misma, atendiendo a las precisiones dogmáticas que ella implica.

\subsection{Convenio Especial de Cooperación en CTeI}

Este convenio está previsto en los artículos 1, 2, 6, 7 y 8 del Decreto-Ley 393 de 1991, al igual que en el artículo 17 del Decreto-Ley 591 del mismo año. Este puede definirse como el acuerdo de voluntades por medio del cual las entidades estatales, entre sí, o con los particulares, se alían con el fin de fomentar y desarrollar un determinado proyecto o programa en materia de CTeI. Para ello, las partes se comprometen respectivamente a aportar a) recursos, a saber, en dinero o en especie o de industria, b) capacidades o c) competencias, sin dar lugar por ello a la creación de nuevas personas jurídicas.

Estos convenios deben constar por escrito, y contener como mínimo: i) objeto, que como se dijo, debe delimitarse al desarrollo de actividades de CTeI; ii) término de duración; iii) mecanismos de administración y contabilidad, por ejemplo, si se utilizará el sistema de encargo fiduciario o cualquier otro para la administración de los recursos, iv) causales de terminación y v) régimen de cesión. Además, en dichos convenios, no existe responsabilidad solidaridad entre las partes (Consejo de Estado, 2015), se debe precisar la propiedad intelectual y moral de los resultados y definirse las obligaciones contractuales que

8 Al respecto se dejará por fuera del presente análisis los convenios de organización de ciencia y tecnología, regulados por los artículos 1 y 3 del Decreto-Ley 393 de 1991, en tanto su carácter no es temporal, al tener como objeto la creación de una nueva persona jurídica. Sobre este tipo de convenios véase Chávez Marín, A. R. (2015). Los Convenios de la Administración. Temis. 
se derivan, en especial las de orden laboral que pudieran generarse de su celebración. Por tratarse de una colaboración mutua, este es un tipo de convenio que no debe generar remuneración para alguna de las partes, ni a manera de honorarios o costos por administración.

En este punto, la Sala de Consulta y Servicio Civil del Consejo de Estado (2017) ha precisado que los convenios especiales de cooperación configuran, materialmente, un tipo de subvención otorgada por la Entidad a su cooperante. Esta subvención está condicionada a un «modus», a saber, la promoción de la ciencia la tecnología y la innovación y, por ello, este se convierte en una obligación o carga jurídica para el cooperante. En este sentido, ha advertido la Sección Tercera del Consejo de Estado (2017) la conveniencia de definir con plena certeza en la minuta de los convenios los efectos del incumplimiento del cooperante, al igual que de considerar el otorgamiento de garantías que aseguren el buen manejo de los recursos públicos allí comprometidos.

Sobre el régimen jurídico de estos convenios, los artículos 7 y 8 del DecretoLey 393 de 1991 disponen que estos se rigen por las normas del derecho privado (Corte Constitucional, 1994 y 1995), con lo cual se reconoce el amplio margen de discrecionalidad del que disponen las partes para que, en virtud del principio de autonomía de la voluntad, definan los elementos del acuerdo negocial. Sin embargo, ello también debe interpretarse de manera sistemática, entendiendo que, en lo que no está expresamente regulado por dichas normas especiales, regirán supletoriamente las disposiciones del EGCAP, tal y como ya se dijo. Como consecuencia de ello, dicho contrato deberá incluir, entre otros asuntos, la disponibilidad y el registro presupuestal correspondientes, en caso de implicar la erogación de recursos públicos, y será objeto del impuesto de timbre nacional. En cumplimiento del principio de publicidad, este deberá publicarse en el SECOP, atendiendo a las normas legales y reglamentarias al respecto.

\subsection{Convenios de financiamiento del desarrollo de actividades de CTeI}

Esta tipología de convenio está prevista en el artículo 8. ${ }^{\circ}$ del Decreto-Ley 591 de 1991, como un mecanismo diseñado para facilitar el fomento de actividades que desarrollen CTeI, mediante la asignación de recursos por parte del Estado, en favor de particulares o de instituciones públicas. En rigor, en estos convenios tampoco se prevé remuneración, sino la mera provisión de recursos, sean monetarios o en especie, para el desarrollo de actividades de CTeI por parte del contratista.

Atendiendo a si dicha asignación de recursos debe reembolsarse y de qué manera, la disposición ya mencionada prevé cuatro modalidades de convenios 
de financiamiento (Presidencia de la República, 1991) ${ }^{9}$ El primero de ellos es el de reembolso obligatorio, en el cual el contratista beneficiario debe pagar los recursos en las condiciones de plazo e interés pactado. El segundo es el de reembolso condicional, en el que el contratante, a través de acto administrativo motivado, puede eximir parcial o totalmente la obligación de pago de capital y/o interés, atendiendo a si el contratista ha tenido éxito en el desarrollo del proyecto.

Una tercera modalidad es la de reembolso parcial. Esta se dirige al financiamiento exclusivo de actividades precompetitivas (etapas de investigación e incluso pilotaje y escalamiento de las actividades de CTeI), de alto riesgo tecnológico, de larga maduración o de interés general directo. Su justificación debe constar en los estudios previos y en el convenio, como estrategia para garantizar su legalidad y facilitar su control. Para estas actividades, la entidad contratante podrá determinar en el convenio la cuantía de los recursos que serán reembolsables. La cuarta y última modalidad se refiere a los convenios de recuperación contingente, en los cuales la obligación de pago de capital e intereses solo surge cuando, a juicio de la entidad contratante, se determine que se ha configurado una de las causales específicas de reembolso que se señalen en el contrato. Para ello se debe expedir un acto administrativo, debidamente motivado, antes del plazo máximo para la liquidación del contrato, donde se establezca el monto del reembolso a realizarse. Dicho acto será de carácter definitivo y procederá exclusivamente el recurso de reposición, conforme al artículo 77 de la Ley 80 de 1993.

Sobre el tema de la propiedad de los aportes hechos en los convenios de financiación, la Sala de Consulta y Servicio Civil del Consejo de Estado (2010) ha sostenido que es posible acordar que los bienes y equipos que se adquieran con dineros del tesoro público pasen a ser de propiedad de los ejecutores de los proyectos, siempre y cuando estos bienes tengan por objeto directo la realización de actividades de CTeI. Por último, debe advertirse que, independiente de la modalidad de convenio de financiamiento que se utilice, en caso de no ejecutarse la totalidad de los recursos aportados para la CTeI, existe la obligación tácita de reintegrarlos a la entidad aportante ante la falta de estipulación contractual al respecto. Ello, según ha sostenido el Consejo de Estado (2017), se fundamenta en la obligación que en este sentido se deriva de la naturaleza del convenio y que, por tanto, solo requiere que se consigne en el acta de liquidación.

9 Estas modalidades están previstas en el artículo 8. ${ }^{\circ}$ del Decreto-Ley 591 de 1991. 


\subsection{Contratos para la administración de proyectos de CTeI}

Estos contratos están expresamente tipificados en el artículo 9. del DecretoLey 591 de 1991. Su fundamento radica en la necesidad o conveniencia que encuentra una entidad estatal para contratar con un tercero idóneo -sea otra entidad pública o un particular-, la administración de un proyecto que desarrolle actividades de CTeI. Esta labor de administración se refiere a diseñar, gestionar, ejecutar, desarrollar y evaluar uno o varios proyectos que ejecuten actividades de CTeI, a cuenta y nombre de la entidad contratante (Chávez, 2015, p. 432).

Este es un típico contrato, en tanto la entidad contratante provee principalmente de recursos al tercero, para que desarrolle sus actividades administrativas, contractuales y operativas de CTeI, a cambio de una remuneración preestablecida. En este sentido, el profesor Dávila Vinueza procede a definirlo como el «vínculo jurídico mediante el cual una entidad del Estado pone a su servicio un particular u otra entidad pública, con el fin de que este, el administrador, desarrolle para aquella el proyecto correspondiente» (Chávez, 2015, p. 432). Por lo tanto, el Consejo de Estado (2017) ha considerado que estos pueden ser calificados como una especie de «contratos de administración delegada», en los cuales la entidad estatal mantiene la titularidad del proyecto y de los dineros destinados para su ejecución, mientras que el tercero solo los administra y ejecuta a cambio de una contraprestación.

En virtud de lo anterior, no cabe duda de que los recursos entregados para la ejecución del proyecto se mantienen vinculados a la titularidad de la entidad contratante, toda vez que el administrador del proyecto actúa como mero administrador de los mismos. De ello se desprende que la principal diferencia de este con las otras tipologías antes expuestas radica en que la iniciativa y titularidad del proyecto es de la entidad contratante, mientras que el contratista presta el servicio de administración. Así, la entidad contratante tiene un amplio margen de intervención en sus directrices, sin soslayar la autonomía técnica y científica que debe tener el administrador.

\subsection{Contratos y convenios celebrados con recursos del Fondo Francisco José de Caldas}

La Ley 1286 de 2009 creó el Fondo Nacional de Financiamiento para la CTeI, Fondo Francisco José de Caldas, como una estrategia para incentivar y unificar los recursos destinados al sector. Al regular el régimen contractual del Fondo, se estableció en el artículo 23 que los actos y contratos que se celebren con recursos del Fondo se sujetarán a las normas de contratación del derecho privado. Ello implica que sean las normas propias del derecho civil y comercial, 
sumadas a la autonomía de la voluntad de las partes, las que determinan el contenido de los contratos y, solo en su defecto, opera, de forma supletoria, el régimen de los contratos y convenios de CTeI.

En este punto, no puede perderse de vista que a la luz de lo dispuesto por el artículo 13 de la Ley 1150 de 2007, el régimen que aplica a dichos contratos no es exclusivamente el derecho privado. Por tratarse de un régimen contractual excepcional, su marco sustancial debe complementarse con los principios de la función administrativa y de la gestión fiscal de que tratan los artículos 209 y 267 de la Constitución Política, así como con el régimen de inhabilidades e incompatibilidades previsto legalmente para la contratación estatal. De igual forma, los litigios relativos a dichos contratos son también de competencia de la Jurisdicción Contencioso-Administrativa y su medio de control es el de controversias contractuales, de conformidad con lo establecido en los artículos 104 y 141 de la Ley 1437 de 2011.

Sobre los tipos de contratos que pueden celebrase con los recursos del mencionado Fondo, valga destacar que ellos podrán coincidir con los de cooperación, financiación o administración o bien configurar otra clase de contratos o convenios, ya que, por mandato legal, lo que debe prevalecer es el origen de los recursos y no las tipologías contractuales definidas legalmente. En cualquier caso, es claro que dichos contratos sí deben tener como objeto específico el fomento de las actividades de CTeI, en los términos antes establecidos, ya que son estas las que sirven de fundamento al Fondo. Estos tipos de convenios y contratos se sintetizan en la tabla 1.

\section{CONCLUSIONES}

A partir de lo expuesto, resulta posible sostener que el régimen contractual de las entidades estatales para el fomento de la CTeI en Colombia tiene dos características principales. En primer lugar, se trata de un régimen contractual especial, en tanto constituye una excepción a los procesos competitivos para la selección del contratista al constituir una causal de contratación directa. Por lo tanto, la aplicación de dicha causal debe ser taxativa y restrictiva, y cumplir, en todo caso, con el principio de selección objetiva.

En segundo lugar, se trata de un régimen reglado, en tanto el ordenamiento vigente define con suficiente precisión varios elementos de este tipo de contratos. En este sentido, se trata de contratos estatales, sujetos al EGCAP; no admiten el pacto ni la utilización de cláusulas excepcionales, requieren de estudios previos y de liquidación, y no es necesario que el contratista esté inscrito en el RUP. Además de ello, y tal vez más relevante, el ordenamiento define las 
Tabla 1. Contratos y Convenios de Ciencia, Tecnología e Innovación

\begin{tabular}{|c|c|c|c|}
\hline \multicolumn{2}{|c|}{ Actividades de CTeI } & \multicolumn{2}{|c|}{$\begin{array}{l}\text { Son aquellas legalmente definidas los D-L } \\
393-91,591 \text { de } 1991 / 91 \text { y L.1286/09. }\end{array}$} \\
\hline Tipologías & Objeto & Régimen jurídico & $\begin{array}{l}\text { Características } \\
\text { comunes }\end{array}$ \\
\hline $\begin{array}{l}\text { Convenio especial de } \\
\text { cooperación }\end{array}$ & $\begin{array}{l}\text { Aunar esfuerzos } \\
\text { técnicos, científicos, } \\
\text { administrativos y } \\
\text { financieros para la } \\
\text { ejecución de } \\
\text { actividades y } \\
\text { proyectos de CTeI. }\end{array}$ & $\begin{array}{l}\text { L.80/93, 1150/07, } \\
\text { D-L. 393/91, } \\
\text { D.1082/15. }\end{array}$ & \multirow{2}{*}{$\begin{array}{l}\text { - Causal de } \\
\text { contratación } \\
\text { directa. } \\
\text { - Requiere de } \\
\text { Estudios Previos. } \\
\text { - Requiere de Acto } \\
\text { Administrativo } \\
\text { que justifique el } \\
\text { contrato. } \\
\text { - No podrán } \\
\text { establecerse } \\
\text { cláusulas } \\
\text { excepcionales. } \\
\text { - Serán objeto de } \\
\text { liquidación. } \\
\text { - Entre otras. }\end{array}$} \\
\hline $\begin{array}{l}\text { Contrato de } \\
\text { financiamiento }\end{array}$ & $\begin{array}{l}\text { Proveer recursos a } \\
\text { una Entidad Estatal o } \\
\text { un particular para el } \\
\text { desarrollo de } \\
\text { actividades de CTeI, } \\
\text { cuyo reembolso } \\
\text { posterior puede ser } \\
\text { obligatorio, } \\
\text { condicional, parcial o } \\
\text { contingente. }\end{array}$ & $\begin{array}{l}\text { L.80/93, 1150/07, } \\
\text { D-L. 591/91, } \\
\text { D.1082/15. }\end{array}$ & \\
\hline $\begin{array}{l}\text { Contrato para la } \\
\text { administración de } \\
\text { proyectos }\end{array}$ & $\begin{array}{l}\text { Proveer recursos a } \\
\text { un tercero idóneo ya } \\
\text { sea una Entidad } \\
\text { Estatal o un } \\
\text { particular para el } \\
\text { desarrollo de } \\
\text { actividades } \\
\text { administrativas, } \\
\text { contractuales y } \\
\text { operativas en CTeI. }\end{array}$ & $\begin{array}{l}\text { L.80/93, 1150/07, } \\
\text { D-L. 591/91, } \\
\text { D.1082/15. }\end{array}$ & \\
\hline $\begin{array}{l}\text { Contratos y } \\
\text { convenios celebrados } \\
\text { con recursos del } \\
\text { Fondo Francisco José } \\
\text { de Caldas }\end{array}$ & $\begin{array}{l}\text { Desarrollar } \\
\text { actividades de CTeI } \\
\text { y ejecutar recursos } \\
\text { provenientes del } \\
\text { Fondo Francisco José } \\
\text { de Caldas. }\end{array}$ & $\begin{array}{l}\text { Ley } 1286 \text { de } 2009 \\
\text { y , D-L. } 393 / 91\end{array}$ & $\begin{array}{l}\text { - Causal de } \\
\text { contratación directa. }\end{array}$ \\
\hline
\end{tabular}

Fuente: elaboración propia.

actividades que pueden desarrollarse en la ejecución de este tipo de contratos y convenios. En esta misma línea, la legislación vigente establece cuatro tipos de contratos de CTeI a saber: i) los convenios especiales de cooperación, ii) los 
convenios de financiamiento del desarrollo de actividades de CTeI, iii) los contratos para la administración de proyectos y iv) los contratos y convenios celebrados con recursos del Fondo Francisco José de Caldas. Para los tres primeros se define legalmente su objeto, los elementos esenciales y el régimen jurídico aplicable. Para el último, lo determinante es que el origen de los recursos sea del Fondo Francisco José de Caldas.

\section{BIBLIOGRAFÍA}

\section{Normatividad y documentos oficiales}

Congreso de la República, Ley 29 de 1990. Por la cual se dictan disposiciones para el fomento de la investigación científica y el desarrollo tecnológico y se otorgan facultades extraordinarias (febrero 27 de 1990).

, Ley 80 de 1993. Por la cual se expide el Estatuto general de Contratación de la Administración Pública (octubre 28 de 1993).

, Ley 1286 de 2009. Por la cual se modifica la Ley 29 de 1990, se transforma a Colciencias en Departamento Administrativo, se fortalece el Sistema Nacional de Ciencia, Tecnología e Innovación en Colombia y se dictan otras disposiciones (enero 23 de 2009).

Ley 1150 de 2007. Por medio de la cual se introducen medidas para la eficiencia y la transparencia en la Ley 80 de 1993 y se dictan otras disposiciones generales sobre la contratación con Recursos Públicos (junio 16 de 2007).

Presidencia de la República, Decreto 591 de 1991. Por el cual se regulan las modalidades específicas de contratos de fomento de actividades científicas y tecnológicas (febrero 26 de 1991).

Decreto 393 de 1991. Por el cual se dictan normas sobre asociación para actividades científicas y tecnológicas, proyectos de investigación y creación de tecnologías (febrero 8 de 1991).

Decreto 1082 de 2015. Por medio del cual se expide el Decreto Único Reglamentario del Sector Administrativo de Planeación Nacional (mayo 26 de 2015).

Colombia Compra Eficiente, Circular Externa Nro. 6. (septiembre 27 de 2013). Disponible en: http:/ / www.colombiacompra.gov.co/sites/cce_public/files/cce_documentos/20161130_manual_de_compra_publica_para_la_innovacion.pdf 


\section{Doctrina}

Chávez Marín, A. R. (2015). Los Convenios de la Administración (3. ${ }^{a}$ ed.). Bogotá: Temis.

Courtis, C. (2006). Observar la ley: ensayos sobre metodología de la investigación jurídica. Madrid: Trotta.

Dávila Vinueza, L. G. (2016). Régimen Jurídico de la Contratación Estatal (3. ${ }^{a}$ ed.). Bogotá: Legis.

Matallana Camacho, E. (2009). Manual de la contratación de la administración pública (2. ${ }^{a}$ ed.). Bogotá: Universidad Externado de Colombia.

Mondragón Duarte, S., Flórez Guzmán, M., \& Plazas Estepa, R. (2020). Los contratos de prestación de servicios estatales en el marco del Covid-19 en Colombia. Revista Republicana, 28(28), 205-215.

Palacio Hincapié, J. A. (2004). La contratación de las entidades estatales (4. ${ }^{a}$ ed.). Medellín: Librería Jurídica Sánchez.

Pino Ricci, J. (2005). El régimen jurídico de los contratos estatales. Bogotá: Universidad Externado de Colombia.

Shick, R. A. (2016). Government Contracting: A Public Solutions Handbook. New York: Routledge.

\section{Jurisprudencia}

Corte Constitucional. Sentencia C-506 de 1994. Magistrado ponente: Fabio Morón Díaz (noviembre 10 de 1994).

Carbonell (julio 19 de 1995).

Sentencia C-316 de 1995. Magistrado ponente: Antonio Barrera

. Sentencia C-316 de 1995. Magistrado ponente: Antonio Barrera Carbonell (julio 19 de 1995).

Corte Suprema de Justicia, Sala Penal. Proceso 37462. Magistrada ponente: María del Rosario González Muñoz (julio 16 de 2014).

Consejo de Estado. Sala de lo Contencioso Administrativo. Sección Tercera. Proceso 16653. Consejera ponente: Ruth Stella Correa Palacio (febrero 11 de 2009). 
(marzo 25 de 2009).

. Proceso 15797. Consejera ponente: Myriam Guerrero de Escobar

. Consejo de Estado. Sala de lo Contencioso Administrativo. Sección Tercera. Expediente 20968. Consejero ponente: Mauricio Fajardo Gómez (mayo 9 de 2012).

. Consejo de Estado. Sala de lo Contencioso Administrativo. Sección Tercera. Proceso 41719. Consejero ponente: Jaime Orlando Santofimio Gamboa (diciembre 2 de 2013).

. Consejo de Estado. Sala de lo Contencioso Administrativo. Sección Tercera. Proceso 50222. Consejero ponente: Mauricio Fajardo Gómez (mayo 14 de 2014).

Consejo de Estado. Sala de lo Contencioso Administrativo. Sección Tercera. Proceso 01704-34649. Consejero ponente: Hernán Andrade Rincón (junio 11 de 2014).

. Consejo de Estado. Sala de lo Contencioso Administrativo. Sección Tercera. Expediente 30589. Consejera ponente: Olga Mélida Valle de la Hoz (junio $1 .^{\circ}$ de 2015).

. Consejo de Estado. Sala de lo Contencioso Administrativo. Sección Segunda. Expediente 0553-12. Consejero ponente: Gabriel Valbuena Hernández (abril 5 de 2017).

Consejo de Estado. Sala de Consulta y Servicio Civil. Concepto 1974. Consejero ponente: Luis Fernando Álvarez Jaramillo (noviembre 26 de 2009).

Consejo de Estado. Sala de Consulta y Servicio Civil. Concepto 2007. Consejero ponente: Enrique José Arboleda Perdomo (julio 8 de 2010).

Procuraduría General de la Nación. Proceso D-2009-878-183667. Ponente: Alejandro Ordóñez Maldonado (julio 18 de 2011).

Trujillo Ardila (abril 16 de 2016).

. Proceso D-2014-120-684737. Ponente: Irma 
